\title{
SEXUALIDADE DO PORTADOR DO VÍRUS DA IMUNODEFICIÊNCIA HUMANA (HIV): UM ESTUDO COM BASE NA TEORIA DA CRISE
}

\author{
Mara Rúbia Ignácio de Freitas ${ }^{2}$ \\ Elucir $\mathrm{Gir}^{3}$ \\ Antonia Regina Ferreira Furegato ${ }^{4}$
}

Freitas MRI, Gir E, Furegato ARF. Sexualidade do portador do vírus da imunodeficiência humana (HIV): um estudo com base na teoria da crise. Rev Latino-am Enfermagem 2002 janeiro-fevereiro; 10(1):70-6.

A investigação teve como objetivo identificar e analisar as dificuldades sexuais e as suas inter-relações com as dificuldades sociais e emocionais vivenciadas por sujeitos em crise de HIV. Os dados foram coletados através de entrevista semi-estruturada, gravada, e após, foram transcritos, categorizados e analisados. Elaboramos a transcrição das falas gravadas, e através da utilização da análise temática, criamos cinco histórias com o título: ..."O viver com HIV". Na análise dos dados a interpretação do conteúdo foi associado ao referencial teórico da crise. Os dados obtidos permitiram concluir que os sujeitos em crise de HIV não conseguiram um nível positivo de adaptação sexual, social e emocional. Na fala desses sujeitos, ficou claro o momento de crise de HIV caracterizada por mecanismos de enfrentamento, geralmente negativos. Os resultados obtidos apontam também para a necessidade de se repensar o papel do enfermeiro frente à intervenção de enfermagem. Acreditamos que o Modelo de Procedimentos de Enfermagem de Saúde Mental, seja adequado para ajudar o sujeito em crise de HIV, na resolução das dificuldades sexuais, emocionais e sociais vivenciadas, e buscar um nível positivo de adaptação e enfrentamento das dificuldades inerentes ou decorrentes da doença.

DESCRITORES: sexualidade, HIV

\section{SEXUALITY OF INDIVIDUALS WITH THE HUMAN IMMUNODEFICIENCY VIRUS (HIV): ONE STUDY BASED ON THE CRISIS THEORY}

The purpose of the investigation was to identify and analize the sexual difficulties and their relation to the social and emotional difficulties experienced by subjects during a HIV crisis. Data were collected through semistructured interviews taped, transcribed, categorized and analyzed. Authors transcribed the conversations using thematic analysis and created five stories entitled: .... "Living with HIV". Data analysis was based on the interpretation of the content associated to the crisis theory. Data enabled authors to conclude that subjects undergoing a HIV crisis did not achieve a positive level of sexual, social or emotional adaptation. The speech of these subjects clearly showed the time of HIV crisis characterized by mechanisms of coping, usually negative. The results also indicate the need to rethink nurse's role, specially nursing intervention. Authors believe that the Model of Mental Health Nursing Procedures is adequate to help subjects in a HIV crisis to solve their sexual, emotional and social difficulties and to search for a positive level of adaptation, considering the difficulties that are inherent to the disease.

KEY WORDS: sexuality, HIV

SEXUALIDAD DEL PORTADOR DEL VÍRUS DE LA IMUNODEFICIENCIA HUMANA (HIV): UNA INVESTIGACIÓN ORIENTADA POR LA TEORÍA DE LA CRISIS

La investigación tuvo como objetivo identificar y analizar las dificultades sexuales y sus inter-relaciones con las dificultades sociales y emocionales vividas por sujetos con crisis de VIH. Los datos fueron recolectados a través de entrevista semi-estructurada, gravada, transcrita, categorizada y analizada. Elaboramos la transcripción de las declaraciones grabadas y haciendo uso del análisis temático construimos cinco historias con el título: .... "El vivir con VIH". En el análisis de los datos la interpretación del contenido fue asociada con el referencial teórico de la crisis. Los datos obtenidos permitieron concluir que los sujetos con crisis de VIH no consiguieron un nivel positivo de adaptación sexual, social y emocional. En las palabras de estos sujetos, quedó claro el momento de la crisis del VIH, caracterizada por mecanismos de enfrentamiento generalmente negativos. Los resultados obtenidos apuntan también hacia la necesidad de re-pensar el papel del enfermero frente a la intervención de enfermería. Creemos que el Modelo de Procedimientos de Enfermería de Salud Mental, sea adecuado para ayudar al sujeto con crisis de $\mathrm{VIH}$, en la resolución de sus dificultades sexuales, emocionales y sociales vividas y buscar un nivel positivo de adaptación y enfrentamiento a las dificultades inherentes o derivadas de la enfermedad.

\section{DESCRIPTORES: sexualidad, VIH}

\footnotetext{
${ }^{1}$ Tese de Doutorado defendida em 9 de junho de 1999, Escola de Enfermagem de Ribeirão Preto da Universidade de São Paulo; ${ }^{2}$ Enfermeiro, Doutor pela Escola de Enfermagem de Ribeirão Preto da Universidade de São Paulo, Professor Adjunto I da UNIP-RP e SENAC-RP; ${ }^{3}$ Professor Livre Docente, e-mail: egir@eerp.usp.br; ${ }^{4}$ Professor Titular. Escola de Enfermagem de Ribeirão Preto da Universidade de São Paulo, Centro Colaborador da OMS para 0 desenvolvimento da pesquisa em enfermagem
} 


\section{INTRODUÇÃO}

AIDS é um fato e, muito mais que uma doença, já se tornou uma grave questão social, pois a maioria dos portadores de HIV é jovem e seu agente etiológico, o Human Immunodeficiency Virus não ataca apenas "certos" grupos ou "certos" indivíduos.

Ao receberem o resultado positivo do exame anti-HIV, os pacientes referiam que a vida acabou. Os sentimentos referidos com maior freqüência são: culpa, remorso, arrependimento, revolta, medo, desespero, desejo de suicídio, negação frente à aceitação do diagnóstico, raiva, agressividade, dor, insegurança, solidão e discriminação, perda do desejo sexual, dificuldade do uso da camisinha, diminuição da atividade sexual ${ }^{(1)}$. Esse quadro afeta 0 equilíbrio do portador de HIV, desencadeando o que se denominou de crise ${ }^{(2)}$. Crises acidentais ocorrem ao acaso, são experiências que constituem ameaça ao equilíbrio físico, psíquico ou social ${ }^{(2-4)}$. Durante as crises acidentais o sujeito pode utilizar-se de seus habituais mecanismos de resolução, tentando solucionar os problemas que o levam à crise; mas quase sempre faltam ao sujeito esses elementos e a pessoa necessitará de ajuda externa ${ }^{(4)}$.

Este estudo se justifica pelo fato dessa infecção/doença ter características devastadoras e ser de competência do profissional da saúde prestar assistência integral de qualidade ao indivíduo em crise, não omitindo a questão da sexualidade e nem tratando-o como ser assexuado. Assim ${ }^{(5-6)}$ os sujeitos em crise podem apresentar dificuldades no exercício da sua sexualidade. Em situações de crise, a sexualidade deve sempre ser estudada e trabalhada, pois, desde 0 nascimento até a morte somos sexuados. A instalação da crise geralmente leva à verbalização da perda da saúde sexual. Considerando que o comportamento sexual pode resultar na infecção pelo HIV, e o HIV constituir-se estímulo desencadeador de crise, afetando inclusive o exercício da sexualidade do seu portador, propusemos esse trabalho, visando buscar subsídios para compreender as dificuldades sexuais e as suas inter-relações com as dificuldades sociais e emocionais vivenciadas pelo portador de HIV. Ressaltamos que através de estudo piloto, anteriormente desenvolvido com portadores de HIV, verificamos que a expectativa quando a coleta do sangue é para teste sorológico anti-HIV e o impacto no momento do conhecimento do diagnóstico desencadeiam a crise. O HIV é o estímulo para que a crise permeie a vida desse sujeito. Dessa forma justificamos que empregaremos ao longo desse trabalho a expressão "crise de HIV".

\section{REFERENCIAL TEÓRICO}

No esquema abaixo, adaptado ${ }^{(7)}$, são evidenciadas as quatro fases durante as quais a pessoa atravessa uma crise da qual poderá sair mais amadurecida, com melhores níveis de saúde, ou menos eficiente, podendo caminhar para uma rotura que poderá levála a manter-se em crise: (Figura 1). Usaremos esse referencial na análise dos resultados.
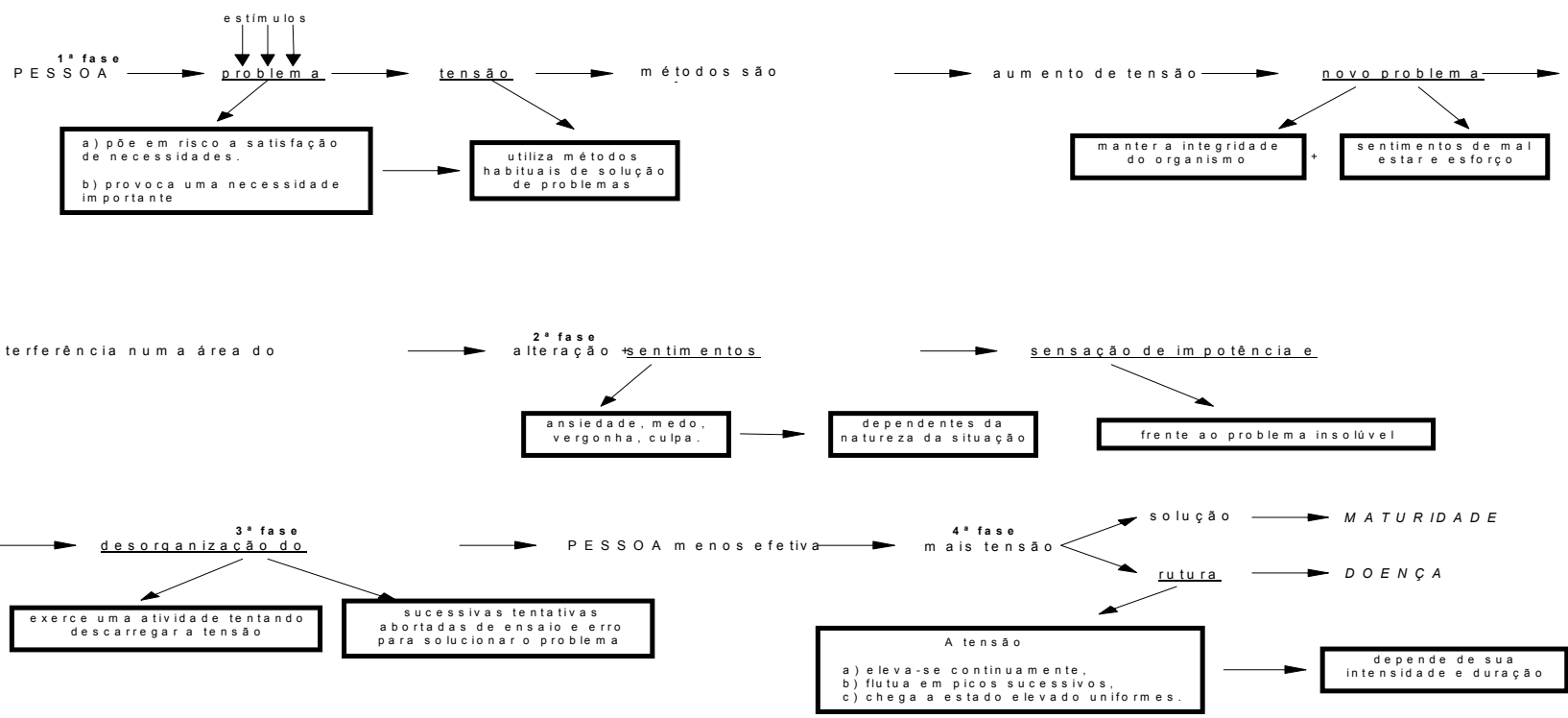

Figura 1 - Processo de Resolução de Problemas (Crise)

Adaptação de: Minzoni MA, Rodrigues ARF, Bucchi M. Pensando em Psiquiatria Preventiva. Enf. Novas Dimensões 1977; 3(3):141-6 ${ }^{(7)}$. 


\section{METODOLOGIA}

O projeto desta pesquisa foi aprovado pelo Comitê de Comissão Ética Médica Centro de Saúde Escola da Faculdade de Medicina de Ribeirão Preto-USP e os sujeitos entrevistados assinaram termo de consentimento. Este estudo foi desenvolvido junto a indivíduos atendidos no ambulatório de Moléstias Infecciosas (MI) de um Centro de Saúde da cidade de Ribeirão Preto, SP. Trata-se de pesquisa de caráter descritivo e insere-se nos pressupostos dos métodos qualitativos de investigação. $\mathrm{Na}$ estratégia da entrevista utilizamos a técnica da "História Oral Temática"(8).

A escolha dos sujeitos para a investigação foi acidental e composta por cinco indivíduos portadores de HIV que fazem seguimento no ambulatório de Moléstias Infecciosas de um Centro de Saúde de Ribeirão Preto, SP. O número de sujeitos foi considerado suficiente quando se verificou que as dificuldades apresentadas pelos participantes tornaram-se repetitivas.

Optamos pela técnica da História Oral Temática, para a coleta de dados assim como na fase de transcrição, textualização e transcriação dos textos com as falas dos sujeitos. A partir de então, foram identificadas as idéias centrais dos depoimentos (núcleos centrais) para caracterizar os conteúdos presentes nas entrevistas, configurando-se, assim, as temáticas ${ }^{(8-9)}$.

Cabe ressaltar que foi realizado um estudo piloto, que evidenciou que o indivíduo, ao saber que é portador de HIV, atravessa um processo de crise, caracterizado pelos elementos característicos de cada período nos seis meses de diagnóstico. Dessa forma, para que pudéssemos identificar os fatores determinantes da crise, optamos por quatro encontros distribuídos nos períodos a saber: a. no dia do conhecimento do diagnóstico pelo paciente; b. em torno de um mês após o diagnóstico; c. em torno de três meses após o diagnóstico; d. em torno de seis meses após o diagnóstico.

Assim, neste estudo, foram entrevistados cinco indivíduos As informações foram obtidas através de entrevistas semiestruturadas, gravadas e transcritas pela própria pesquisadora, onde foi solicitado ao sujeito o relato de sua vida referente aos aspectos sexual, social e emocional, antes e depois de ser portador de HIV. Essas transcrições gravadas foram feitas imediatamente após cada sessão, seguida da conferência de fidedignidade e possíveis correções, evitando-se, pois, a perda das expressões dos pacientes ${ }^{(10)}$.

Foi feita a análise temática compreensiva dos dados significativos desses agrupamentos, tendo como base a interpretação do conteúdo associado ao referencial teórico da crise ${ }^{(7)}$. A sexualidade, tema principal da nossa pesquisa, emergiu e foi compondo, junto com os autores do referencial teórico estudados, um dos fatores da crise de HIV. Sob essa ótica, a análise deste trabalho orientou-se na compreensão da Crise de HIV e das dificuldades sexuais, emocionais e sociais dos portadores.

Considerando-se 0 embasamento teórico proposto e 0 objetivo do presente trabalho, três categorias emergiram e foram denominadas: Categoria A - Dificuldade Sexual; Categoria B Dificuldade Emocional; Categoria C - Dificuldade Social.

Os dados foram submetidos à validação por especialista em pesquisa qualitativa e teoria da crise. Após ser instruída para que julgasse as categorias de modo a verificar a concordância ou não com os corpus, bem como a adequação das unidades de fala dentro das subcategorias, a especialista avaliou a adequação das mesmas ao núcleo temático e ao referencial teórico escolhido.

\section{ANÁLISE E DISCUSSÃO DOS RESULTADOS}

O grupo de portadores de HIV desse estudo foi constituído por três sujeitos femininos e dois masculinos, todos declararam ter orientação heterossexual.

Após a análise de conteúdo das falas, foram identificadas seis subcategorias que foram então agregadas em três categorias.

$\mathrm{Na} 1^{\text {a }}$ fase do referencial, analisamos as falas do primeiro encontro que efetuamos junto aos sujeitos em crise de HIV. Há elevação inicial da tensão (impacto do estímulo) e entram em ação as respostas homeostásicas habituais para solução de problemas ${ }^{(7)}$.

No segundo encontro, ocorrido após um mês do diagnóstico de HIV, ( $2^{\mathrm{a}}$ fase), o indivíduo não obtém êxito e o estímulo (crise de HIV) continua, ocorre um aumento de tensão que pode levá-lo a um estado de alteração e sensação de incapacidade. Na terceira fase analisamos o terceiro encontro que ocorreu três meses após 0 diagnóstico de HIV. O problema continua sem solução, haverá novo aumento de tensão. Esta provocará a mobilização de recursos internos e externos no sentido de solucioná-la.

O último e quarto encontro com os portadores de HIV, ocorreu seis meses após o sujeito ter conhecimento do diagnóstico. Existem momentos que se nenhum dos recursos utilizados, até então, foram suficientes para enfrentamento da crise, poderá haver elevação da tensão até o ponto de rutura, com conseqüente desorganização do indivíduo ${ }^{(7)}$. Uma crise pode mudar repentinamente a personalidade do indivíduo que, de modo geral, sofre um processo contínuo de evolução e amadurecimento. As mudanças ocorridas em razão de um problema podem levar a maior maturidade ou, ao contrário, a uma redução da capacidade do indivíduo para enfrentar outros problemas de maneira eficiente.

Os nomes dos portadores de HIV citados no texto são fictícios. Com referência ao primeiro encontro com o sujeito e a primeira fase do referencial, descrevemos a categoria A: "Dificuldade 
sexual" e a subcategoria A1: "Vida sexual mudou após o diagnóstico". Os cincos informantes desse primeiro encontro manifestaram que sua vida sexual realmente mudou após o diagnóstico, como se observou nas falas a seguir: diminuiu sexo, também está muito recente, perco a vontade e o desejo (Leonardo). Não pretendo ter relações tão cedo, relação sexual para mim já era, sinceramente o desejo, a vontade acabou (Sônia). Paramos as relações sexuais, eu tenho vontade, eu quero voltar a ter relações sexuais (Estela).

A categoria B - "Dificuldade emocional", no primeiro encontro, foi analisada pelas falas incluídas na subcategoria B1 "Alterações psicológicas que afetaram a vida sexual" (por exemplo: discriminação, negação, culpa, medo, angústia, morte)....Não pretendo ter relações sexuais tão cedo, porque vou ter que falar o que tenho e vai dar briga, tenho medo de falar o que tenho e as pessoas se afastarem (Sônia). Paramos as relações sexuais, eu quero voltar a ter relações com ele (Estela).

$\mathrm{Na}$ fala desses sujeitos podemos notar problemas referentes à ansiedade, insegurança, tensão, medo da rejeição, negativismo, prostração, isolamento, diminuição do desejo sexual, angústia, anorexia, medo do emagrecimento, insônia, choro, apatia. De acordo com a $1^{\text {a }}$ fase do referencial esses problemas desencadeiam a crise e esses sujeitos podem buscar solução. Os portadores de HIV são confrontados com múltiplos estressores psicossociais em todas as fases da infecção. Certos estressores alteram o estilo de vida e exigem adaptações ${ }^{(11)}$.

Sobre a categoria C - "Dificuldade Social", ainda no primeiro encontro, analisamos as falas da subcategoria C1 - "Alterações sociais que afetaram a vida sexual" (por exemplo: isolamento, afastamento de amigos, problemas com familiares, amigos próximos, desemprego). ...mudou o meu modo de agir e pensar; eu saía muito, transava, bebia, rolava de tudo, mudei completamente, não saio mais, hoje penso em prevenção (Leonardo). Sexo acabou, parei de beber, de sair à noite, o erro que aconteceu comigo não quero para ninguém (Sônia). 0 medo de contagiar o parceiro(a) pode motivar o distanciamento físico e restringir a intimidade sexual ${ }^{(12)}$.

$\mathrm{Na}$ categoria A - "Dificuldade sexual", foi apresentada a subcategoria A2 - "Prevenção: fatores ligados à transmissão sexual", conforme observamos nas falas a seguir: estou me resguardando mais, hoje penso assim, poxa vida eu sou uma pessoa contaminada, eu contamino as pessoas, isso me remói, é psicológico, perco a vontade, o desejo, nem sempre tinha camisinha no carro, foi uma vacilada que eu dei (Leonardo). Ele aceita o preservativo, eu não gosto, meu maior desejo é fazer sexo sem camisinha, ele fala que é higiênico, nunca usei camisinha, é estranho (Helena). É importante destacar que os cinco informantes relataram que não usavam o condom. Falaram também que agora, após 0 diagnóstico, estão fazendo uso do condom. Durante as entrevistas muito se falou sobre as formas de prevenção e a utilização do condom para impedir a transmissão sexual do HIV ou evitar exposições repetitivas ao vírus.

Referente à categoria B - "Dificuldade emocional" analisamos a subcategoria B2 - "Aspectos psicológicos frente à prevenção sexual". Nas seguintes falas: ninguém usa camisinha, nem eu usei, sexo acabou, quero distância, peguei isso pelo sexo, cacei sarna, eu não tenho cura, parei de sair, namorar, eu me isolei (Sônia). Nem sempre usava camisinha, meu Deus porque foi acontecer isso, por que comigo? Não deve ser verdade. Até pensei em suicídio, não sei se vou viver 2 meses, agora que tudo ia tão bem fui dar uma vacilada, não usei camisinha (Leonardo).

Na categoria C - "Dificuldade social" apresentamos as falas da subcategoria C2 - "fatores sociais quanto à prevenção sexual". Eu não tenho cura, parei de sair, de namorar, eu me isolei (Sônia). Eu saía com várias garotas, não usava camisinha, não saio mais (Maurício). Tanta gente está sofrendo por culpa minha, meu marido, meus pais, meu marido, eu não usei camisinha (Helena).

No segundo encontro, segunda fase do referencial, encontramos os sujeitos buscando a organização e com a crise de HIV instalada e verbalizada com mais facilidade. Os informantes já receberam o exame confirmatório. Na categoria A - "Dificuldade sexual", a subcategoria A1 "Vida sexual mudou após o diagnóstico" foi analisada frente às falas colocadas a seguir e contrapondo com as falas do primeiro encontro: acho difícil ter atividade sexual, agora estou chocado, sozinho" (Leonardo). Sexo nem pensar, nunca mais (Sônia).

É importante ressaltar que vários autores ${ }^{(1,11,13)}$ salientam que o medo frente à transmissão sexual aumentou com a aids, tanto em sujeitos infectados, como não infectados. É comum encontrarmos indivíduos que bloquearam as atividades sexuais (como nas falas acima citadas) ou então sujeitos que fazem sexo e têm o desempenho prejudicado. Trata-se de uma fobia à aids que tem se alastrado por todo o mundo sem necessariamente estarem em risco ou infectados. Esses comportamentos mostram o momento da crise ${ }^{(2)}$ vivenciado pelos portadores de HIV.

A categoria B - 'Dificuldade emocional" encontra-se verbalizada nas falas que compõem a subcategoria B1 - "Alterações psicológicas que afetaram a vida sexual" (medo, inconformismo, discriminação, rejeição). ....Como vou contar o que tenho? Acho difícil ter relação agora, como vou contar, não posso mentir, é difícil a outra pessoa aceitar. Agora tenho medo de me relacionar, estou sozinho, mais tarde, se eu estiver bem, posso pensar em correr o risco. ... um sim ou um não, mudou tudo, piorou, vivo com medo (Leonardo).

No segundo encontro, na categoria C - "Dificuldade social", descrevemos as falas da subcategoria C1 - "Alterações sociais que afetaram a vida sexual" (isolamento social). Eu saía, fazia noitadas, hoje não faço mais nada, mudou tudo; diminuíram as relações sexuais, eu queria até me separar dele (Helena). Em casa, está uma barra, não é fácil, tomo calmante e não durmo, tudo mudou (Estela). 
Na categoria A - "Dificuldade sexual", encontra-se a subcategoria A2 - "Prevenção: fatores ligados à transmissão sexual" tal como expresso nas unidades de fala: Sai com várias garotas e nunca me preveni, (Maurício). Meu filho (5 meses) ainda é soropositivo, eu fico me sentindo culpada (Helena). Eu peguei do meu marido, nem temos mais relação sexual (Estela).

No segundo encontro, a categoria B - "Dificuldade emocional", extraímos as unidades de fala da subcategoria B2 "Aspectos psicológicos frente à prevenção sexual" (preocupação, medo, conformismo, discriminação, rejeição). Acho que estou mais conformada, não aceitava que meu filho ainda é soropositivo, agora tenho esperança. Antes era pior, agora penso: HIV é ser uma pessoa diferente, é ter cuidados para não contaminar os outros e quando eu me corto fico preocupada com as crianças. (Helena). Se eu não tivesse transado, caçado sarna, a nossa vida não estava escumungada (Sônia).

Podemos observar que nesse segundo encontro a crise é verbalizada com facilidade. Sentimentos como medo da revelação do diagnóstico, solidão, medo de contaminar outras pessoas estão presentes nas falas caracterizando a segunda fase do referencial teórico adotado. Alguns fatores psicológicos podem interferir na sexualidade desse sujeito e prejudicar o retorno à atividade sexual com ansiedade grave ou medo em relação à capacidade de realizarse, rejeição do parceiro sexual e medo do parceiro sexual em relação ao $\mathrm{HIV}^{(12)}$.

Segundo encontro. Na categoria C - "Dificuldade social", desenvolvemos análises das unidades de fala da subcategoria C2 "Aspectos sociais frente à prevenção sexual (isolamento social por medo de rejeição, preconceito). Tenho medo de me relacionar, prejudicar mais alguém, não quero contar para ninguém (Leonardo). Tenho medo de me envolver, quero me isolar, não quero que saibam (Sônia).

No terceiro encontro analisamos a categoria A - "Dificuldade sexual" nas falas agrupadas na subcategoria A1 - "Vida sexual mudou após o diagnóstico". O organismo exige que você tenha relação sexual com alguma pessoa. É a mesma coisa quando dá fome, eu não superei essa parte. É a pior fase que estou passando (Leonardo). Sexo melhorou, ele me procurou, fingimos que não existe HIV, mas quando lembro, é duro, é difícil (Estela). Essas falas evidenciaram as mudanças ocorridas na vida sexual desses informantes. Desde o primeiro até o terceiro encontro esses sujeitos referiram diminuição ou encerramento das relações sexuais. De acordo com o referencial na segunda fase, a crise está instalada. Observamos que esses sujeitos não conseguiram solucionar os problemas e experimentam a sensação de impotência frente a crise HIV.

$\mathrm{Na}$ categoria B - "Dificuldade emocional", enfatizamos as falas da subcategoria B1 - "Alterações psicológicas que afetam a vida sexual". Qual ser humano que não quer ser amado, é uma grande crise na minha cabeça. A crise maior é como me relacionar com alguém, não conversei com ninguém, a não ser aqui com você, é dificili, não sei como resolver (Leonardo). Sexo melhorou, fingimos que não lembramos do HIV, mas de repente bate aquela tristeza (Estela). Eu uso camisinha; psicologicamente é ruim, mas não tem outro jeito (Helena).

Na categoria C - "Dificuldade social" situamos as falas da subcategoria C1 - "Alterações sociais que afetaram a vida sexual". Estou na paquera com uma pessoa, mas ainda não saímos, não aconteceu, mas é uma crise que eu não sei (Leonardo).

No terceiro encontro analisamos a categoria A - "Dificuldade sexual" nas falas agrupadas na subcategoria A2 - "Prevenção: fatores ligados à transmissão sexual". Se você põe na cabeça que quer transar e não tem com quem ter, aí já vou ficando biruta, pirada, masturbar não resolve (Sônia). Usamos camisinha sempre, incomoda, voltamos a fazer sexo, ele põe a camisinha" (Estela). Eu uso camisinha, não acho tão ruim como antes, eu lembro que uso porque tenho isso, para ninguém é normal (Helena).

Ainda no terceiro encontro analisamos a categoria B "Dificuldade emocional" nas falas da subcategoria B2 - "Aspectos psicológicos frente à prevenção sexual" (preocupação, medo, incerteza). Tenho dificuldade de contar que tenho HIV e me relacionar com outras pessoas intimamente (Leonardo). Camisinha incomoda, eu e ele não gostamos, mas usamos, acho que ninguém gosta (Estela). Autores ${ }^{(14-15)}$ citam que revelar algo não aceito socialmente pode levar o parceiro sexual a rejeitar 0 outro.

No quarto encontro analisamos as falas das 6 subcategorias contidas nas três categorias. Subcategoria A1 - "Vida sexual mudou após o diagnóstico" da categoria A - "Dificuldade sexual". Agora fico preocupada com as coisas, antes era melhor, eu não passava tão mal com os remédios. É difícil ter relações sexuais com tantos problemas, tem dia que dá certo, 1 relação sexual por semana, mas eu não sinto bem como antes (Estela). Se um dia eu arrumar um namorado, se eu tiver que transar, eu não quero, se ele me amar, vai entender e me ajudar, mas isso é impossivel, essa doença é dificil, os outros não entendem como se transmite (Sônia). Além da diminuição sexual, esses sujeitos referiram que antes do HIV a atividade sexual era melhor não apenas na quantidade mas na qualidade.

O sujeito em crise tenta com recursos próprios a busca de adaptação, sendo que no presente estudo as falas dos sujeitos evidenciam a busca sem sucesso.

Analisamos, no quarto encontro, a categoria B - "Dificuldade emocional" nas falas da subcategoria B1 - "Alterações psicológicas que afetaram a vida sexual" (conformismo, medo, tristeza, desânimo, preocupação, brigas). É difícil ter relação sexual com tantos problemas, 
não faço mais nada, não dá tempo, mas estou conformada, vou fazer o quê?

(Estela). Sexo agora que não quero, José já tentou, perguntou se eu morri para a vida, minha cabeça não está boa para isso, eu quero paz (Sônia).

O esperado é que a pessoa tenha suficientes recursos físicos, boas relações interpessoais, com adequadas vinculações emocionais numa sociedade estável, que tenha mais instrumentos perceptivos, mais habilidades para resolver problemas e valores que a orientarão na luta pela vida ${ }^{(4)}$.

Ainda no quarto encontro, analisamos as falas da categoria C - "Dificuldade social" da subcategoria C1 - "Alterações sociais que afetaram a vida sexual". Essa doença é dura, a gente não sabe a reação das pessoas, não vou correr o risco, não quero sexo com ninguém (Sônia). Estou sentindo dificuldade para dizer para as pessoas e para relacionar-me intimamente com alguém, só desabafo aqui, fora daqui não converso com ninguém (Leonardo). Voltou o herpes, estou com medo (Maurício).

Acreditamos que o medo da transmissão do HIV por via sexual e o receio de contatos sociais que evidenciam a rejeição e a discriminação ao revelarem sua contaminação pelo HIV, levaram os informantes a referirem disfunções sexuais tais como: inapetência (perda do desejo), insuficiência erétil, falta de lubrificação (perda da excitação), distúrbios de ejaculação, anorgasmia, vaginismo e dispareunia (dor no coito) ${ }^{(13)}$.

A categoria A - "Dificuldade sexual" nas falas da subcategoria A2 - "Prevenção: fatores ligados à transmissão sexual" (medo da transmissão, uso de camisinha, evitar contatos sexuais). Não quero transmitir para ninguém (Sônia). Às vezes eu vou ao banheiro e resolvo lá mesmo, não corro o risco de passar para ela, mas sexo melhorou, conseguimos ter relação, mas como eu piorei, comecei a pôr 2 camisinhas, o meu medo me deixa louco, estou evitando ao máximo procurar ela ainda mais agora com esses sintomas (Maurício).

Com base no quarto encontro analisamos a categoria B "Dificuldade emocional" na subcategoria B2 - "Aspectos psicológicos frente à prevenção sexual". O meu medo me deixa louco, estou evitando procurar ela, coloco 2 camisinhas quanto tenho relação sexual com ela, depois arrependo por ela correr o risco (Maurício). Todos sofrendo por culpa minha. Se eu tivesse evitado...! (Helena). Sonho em parar de usar camisinha, voltar ao normal (Helena).

O quarto e último encontro permitiu-nos evidenciar e analisar a categoria $\mathrm{C}$ - "Dificuldade social" nas falas da última subcategoria C2 - "Fatores sociais quanto à prevenção sexual" (participação de grupos, falta de comunicação, preocupação). Estou indo no grupo de apoio, aprendo sobre prevenção e acho que vendo problemas piores, pode ajudar a aceitar o meu (Estela). Eu finjo que tive orgasmo, não quero falar com meu marido agora, não quero me preocupar com mais isso (Helena). Não quero sexo, não quero transmitir para ninguém (Sônia).

Com base nos autores citados e nas falas transcritas, percebemos que os sujeitos em crise, utilizaram métodos para tentar solucionar os problemas e, mesmo com o HIV presente, esses indivíduos podem se manter em desequilibrio ou buscarem o equilibrio relativo, já que a aids ainda não tem cura. Salientamos que o enfermeiro pode intervir, quando solicitado, junto ao portador HIV em crise; o que requer competência e preparo sobre o tema sexualidade e crise.

\section{CONSIDERAÇÕES FINAIS}

Ao concluir este trabalho, visualizamos que os sujeitos em crise HIV, ao receberem o resultado do exame anti-HIV, no primeiro encontro, referiram que "é como receber uma sentença de morte"; "parecia que estavam me velando viva", ou seja, a sensação era de que a vida acabou. 0 paciente não tem, nesse momento, condição de reflexão e elaboração de como enfrentar as dificuldades sociais, emocionais e principalmente as dificuldades sexuais. Esses sujeitos, durante os quatro encontros que analisamos, percorreram o Processo de Resolução de Problemas (crise). Analisando de maneira concisa os dados, sob a ótica da "Teoria da Crise" ${ }^{(2,4-6,16)}$ consideramos que os sujeitos não demonstraram um nível positivo de adaptação sexual, social e emocional.

Durante a análise das falas contidas nas subcategorias, esses sujeitos fizeram referências às tentativas de adaptação à nova condição. As dificuldades descritas nas três categorias levam a entender que o modo de viver do sujeito em crise de HIV, no momento das entrevistas, caracterizava-se por mecanismos de enfrentamento, geralmente negativos, sem apoio e intervenção adequados dos profissionais que os assistiram.

Para que o enfermeiro desempenhe com sucesso seu papel na relação de ajuda, é importante que ele saiba ouvir com atenção os dados da vivência da crise do indivíduo. O Modelo de Procedimentos de Enfermagem de Saúde Mental (MPESM) proposto ${ }^{(4)}$, possibilita a intervenção na crise de HIV, através da relação de ajuda.

Acreditamos que se usarmos, no momento adequado, os passos descritos no modelo proposto ajudaremos o sujeito em crise de HIV a superar o episódio de desequilíbrio a curto, médio ou a longo prazo. A integridade sexual da pessoa em crise necessita ser percebida e compreendida pelo enfermeiro, a fim de que as ações de enfermagem contemplem o ser integral (física, psicológica e social). Com base nesses resultados, propomos a aplicação desse modelo de assistência, a fim de que possamos ajudar o sujeito em crise de HIV na resolução das dificuldades sexuais, emocionais e sociais vivenciadas, buscando um nível positivo de adaptação e enfrentamento das dificuldades inerentes ou decorrentes da doença. 


\section{REFERÊNCIAS BIBLIOGRÁFICAS}

1. Ostrow DG. Psychiatric considerations in human immunodeficiency virus disease. In: De Vita V Junior, Hellman S, Rosenberg SA. AIDS: etiology, diagnosis, treatment and prevention. 4.ed. Philadelphia(USA): Lippincott - Raven; 1997. p.541-50.

2. Caplan G. Principles of preventive Psychiatry. New York (USA): Basica Books; 1966.

3. Erikson EH. Identidade, juventude e crise. Rio de Janeiro (RJ): Zahar; 1972. 230p.

4. Rodrigues ARF. Enfermagem psiquiátrica em saúde mental: prevenção e intervenções. São Paulo (SP): EPU; 1996.

5. Infante MS. Crisis theory: a framework for nursing practice. Virginia: Reston; 1982.

6 Hoff LA. People in crisis: understanding and helping. 3.ed. California: Addison Wesley; 1989. 463p.

7. Minzoni MA, Rodrigues ARF, Bucchi M. Pensando em psiquiatria preventiva. Enf Novas Dimensões 1977; 3 (3):141-6.

8. Meihy JCSB. (Re) introduzindo história oral no Brasil. São Paulo(SP): Xamã; 1996.

9. Bardin L. Análise de conteúdo. São Paulo (SP): Edições 70; 1994.
10. Freitas MRI, Carvalho EC, Pelá NTR. Aceitabilidade do emprego da técnica do gravador no registro da informação viva. Anais do $3^{\circ}$ Simpósio Brasileiro de Comunicação em Enfermagem; 1992; Ribeirão Preto (SP): 1992. p.299-310.

11. Gir E. A sexualidade e a mulher portadora do vírus da Imunodeficiência Humana Tipo 1 (HIV). [tese] .Ribeirão Preto (SP): Escola de Enfermagem de Ribeirão Preto/USP; 1997.

12. Doll SL, Dillon BA. Counseling persons seropositive for human immunodeficiency virus infection and their families. In: De Vita VT, Hellman S, Rosenberg SA. AIDS: etiology, diagnosis, treatment prevention. 4.ed. Philadelphia (USA): Lippincott; 1997. p.533-9.

13. Lopes GP. Patologia e terapia sexual. São Paulo (SP): Medsi; 1994.

14. Kolodny RC, Masters WH, Johnson UE. Manual de Medicina sexual. São Paulo (SP): Manole; 1982.

15. Hogan R. Human sexuality: a nursing perspective. 2.ed. Connecticut (USA): Appleton-Century-Crofts; 1991.

16. Jacobson GF, Strickler M, Morley WF. Generic and individual approaches to crisis intervention. Am J Public Health 1968; 58(2):33843. 